\title{
Familial Predisposition of Primary Dysmenorrhea among Senior High School Girl Students
}

\author{
Prema Sharlini, ${ }^{1}$ Hadyana Sukandar, ${ }^{2}$ Ryadi Fadil, ${ }^{3}$ \\ ${ }^{1}$ Faculty of Medicine, Universitas Padjadjaran, ${ }^{2}$ Department of Epidemiology and Biostatics \\ Faculty of Medicine Universitas Padjadjaran, ${ }^{3}$ Department of Child Health Faculty of Medicine \\ Universitas Padjadjaran/Dr. Hasan Sadikin General Hospital Bandung
}

\begin{abstract}
Background: Dysmenorrhea is a common female reproductive problem in women of active reproductive age which is characterized by menstrual pain or cramps in a women's lower abdomen or back. Dysmenorrhea can be classified into primary and secondary. One of the associated risk factor of primary dysmenorrhoea is the family history, however the study on the family history of primary dysmenorrhea with recurrent menstrual pain is limited. This study was conducted to identify the correlation between family history and primary dysmenorrhea in high school girls.

Methods: This cross sectional study was conducted at several senior high schools in Jatinangor from AprilJune 2013. One hundred and sixty two students were included in this study. The sample size was calculated based on the unpaired-dichotomous variable for the two-sided formula. A self administered questionnaire was distributed to the senior high school girl students who were in their menarche age, menstrual cycle characteristics, presence or absence of dysmenorrhea, severity of pain and presence dysmenorrhea in mothers and in sisters were inquired. Data were analyzed using chi square test.

Results: Overall, there were association between positive family history and primary dysmenorrhea among the students with $(\mathrm{p}<0.001)$. The prevalence of dysmenorrhea in the students was $92.6 \%$ with $95 \%$ confidence interval which was $87.5-95.7 \%$. The prevalence rate was $67.9 \%$ in mothers with $95 \%$ confidence interval which is $60.4-74.6 \%$ and $80.2 \%$ prevalence of primary dysmenorrhoea in sisters with $95 \%$ confidence interval which is $73.4-85.6 \%$.

Conclusions: There is a significant association between positive family history and primary dysmenorrhea. [AMJ.2015;2(4):579-83]
\end{abstract}

Keywords: Family history, senior high school students, primary dysmenorrhea

\section{Introduction}

Dysmenorrhea is a common female gynaecological problem defined as painful menstruation. ${ }^{1}$ Dysmenorrhea can be classified into primary dysmenorrhoea which is a natural process of menstruation and usually described as colicky, spasmodic cramping felling in the abdomen, back and pelvic areas, while secondary dysmenorrhoea is caused by pelvic pathologic conditions. ${ }^{2}$ Primary dysmenorrhea has a prevalence rate ranges from 40 to $90 \%{ }^{3}$ It is the foremost cause of frequent temporary absenteeism from school and work. In a previous study, it was reported that adolescent girls tend to have a higher prevalence of primary dysmenorrhea than older women. ${ }^{4}$
The exact cause of primary dysmenorrhea is not particularly understood, but the mechanism of the pain generation in patients with dysmenorrhea can be explained by the secretion of prostaglandin (PG) especially $\mathrm{PGE}_{2}$ and $\mathrm{PGF}_{2} \alpha$ which will result in myometrial hyper contractility and pain. In some studies, it is also stated that it is resulted from uterus hypoxia, ischemic and vasopressin which results in myometrium hypersentivity and causes myometrium hypercontractility and producing pain. ${ }^{5}$ Generally the risk factors mentioned in previous studies are early age of menarche, heavy menses, younger age $(<20)$ years old, smoking and strong family history. The research on the association of family history in occurrence of dysmenorrhea and severity of condition is still limited. Therefore,

Correspondence: Prema Sharlini, Faculty of Medicine, Universitas Padjadjaran, Jalan Raya Bandung-Sumedang Km.21, Jatinangor, Sumedang, Indonesia, Phone: +6285722585984 Email: prema1691@gmail.com 
this study was conducted to determine the correlation between family history and primary dysmenorrhea among the senior high school girl students.

\section{Methods}

This cross sectional study was a part of bigger research conducted by Nutritional and Reproductive Working Group on Jatinangor Cohort, especially Puberty Survey by Department of Epidemiology and Biostatics, Faculty of Medicine,Universitas Padjadjaran. It was carried out at several senior high schools from April-June 2013 in Jatinangor. A total of one hundred and ninety nine students were participated in this study. The sample size was calculated based on the unpaireddichotomous variable for the two-sided formula. Therefore, the minimum sample size needed for this study was hundred and forty two participants.

Students were included from the age 15-17 years who already had menarche, healthy students without any other medical illness and has mother who was still in menstrual productive age and female siblings who has their menarche. The exclusion criteria were respondents with irregular menstrual cycles. This was determined based on the duration of the menstrual periods. The menstrual period was categorized as short menstrual period when it was less than 2 days, 2-6 days were categorized as normal duration of menstrual period and more than 6 days as longer duration of menstruation. Respondents with other underlying diseases such as secondary dysmenorrhea were also excluded as this research was mainly concerned with primary dysmenorrhea to detect the familial risk. This was categorized based on the onset of painful menstruation, as primary when the menstrual pain present and started since menarche or 1 to 3 years after menarche and secondary if the pain present only 3-5 years after menarche.

Subjects were also excluded if they smoke cigarette, consuming alcohol and has menarche before 9 years old. The gap between two consecutive cycles was also questioned to inquire the regularity of the menstrual cycle. The regularity of the menstrual cycle was categorized based on the gap between the two consecutive cycles. Short cycle was defined as less than 21 days, normal cycle as 21-35 days and a longer cycle was categorized as more than 35 days. Students were included from the age 15-17 years who already had menarche, healthy students without any other medical illness and has mother who was still menstrual productive age and female siblings who has their menarche.

Thirty seven students were excluded from one hundred and ninety nine students participated. A self designed questionnaire was administered to the students from all the classes, who were chosen by simple random sampling. The subjects were between 15-17 years old who met the inclusion criteria and were not excluded based on the exclusion criteria. The students were asked about their menarche age, menstrual period, presence or absence and if it was presence, the characteristics of dysmenorrhea were also asked to determine whether primary or secondary. Concerning the positive family history of dysmenorrhea, presence of dysmenorrhea in the student's mothers and a female sibling were assessed with a self administered questionnaire.

The severities of dysmenorrhea were determined by classifying pain into six classes based on Wong-Baker Faces Pain Scale as 0 means no hurt, 2 means hurts a little, 4 means hurts a little more, 6 means hurts even more, 8 means hurts a whole a lot, and 10 means hurts worst. $^{8}$

This study was approved by the Health Research Ethic Committee of Dr. Hasan Sadikin General Hospital, Bandung. Before conducting the survey, approvals were also obtained from the school's top officials. The explanations on the objective, goals and techniques of answering the validated and reliable questionnaires were given to the respondents to obtain their informed verbal consent.

There were 162 students who meet the inclusion criteria. For the statistical analysis, Software Package used was Statistical Analysis Version 15 (SPSS 15). The content of each tool were categorized and analyzed by chi square test. It was also used to find the prevalence ratio and $95 \%$ confidence interval. The descriptive statistics was used to analyze the severities of dysmenorrhea in the respondents. Statistically significance was considered when $\mathrm{p}<0.05$.

\section{Results}

Painful menstruation due to primary dysmenorrhea was seen in 150 (92.6\%). The number of cases with positive family history of primary dysmenorrhea was more than those without family history of dysmenorrhea. There were 85 students who both mothers 
Table 1 Association between Positive Family History and Primary Dysmenorrhoea in Students with and without Dysmenorrhea

\begin{tabular}{lcccc}
\hline \multicolumn{1}{c}{ Variables } & Cases N (\%) & Dysmenorrhea & $\begin{array}{c}\text { Without } \\
\text { Dysmenorrhea }\end{array}$ & $\mathbf{P}^{*}$ \\
\hline Mother & & & & \\
Yes & $110(67.9 \%)$ & $108(66.7 \%)$ & $2(1.2 \%)$ & $<0.001$ \\
No & $52(32.1 \%)$ & $42(25.9 \%)$ & $10(6.2 \%)$ & \\
Sister & & & & \\
Yes & $130(80.2 \%)$ & $125(77.2 \%)$ & $5(3.1 \%)$ & $<0.001$ \\
No & $32(19.8 \%$ & $25(15.4 \%)$ & $7(4.3 \%)$ & \\
\hline Note: *hi square test & & & &
\end{tabular}

and sisters had dysmenorrhea. A positive correlation was found between primary dysmenorrhea and positive family history as presented in (Table 1). Chi square test was significant with $\mathrm{p}<0.001$.

Most of the students complained painful menstrual cramps suffer from moderate pain. There were also a number of students who had severe pain. Most of the students reported severity of menstrual pain as hurts a little bit and hurts a little more (Table 2).

\section{Discussion}

Dysmenorrhea which means painful menstrual cramps of uterine origin is a common reproductive illness of women in reproductive age. ${ }^{9}$ There were 150 students $(92.6 \%)$ who suffered primary dysmenorrhea.

This is a very high prevalence compare to a previous study reported in a study conducted among adolescent girls in Suburban districts of Tehran ${ }^{10}, 71.0 \%$. Similarly it was observed in a study conducted in New Zealand ${ }^{11}$ stated that the prevalence rate of primary dysmenorrhea is estimated varies from $45.0 \%$ to $95.0 \%$. This is because the subjective aspect of painful menstrual cramps is hard to determine because varied definitions of the condition.

Another study was performed in 2010 in Omani ${ }^{12}$ which had as much as $94.0 \%$ of prevalence rate, whereas similar frequency were reported in present study, 92.6\% ${ }^{13} \mathrm{~A}$ study conducted among a group of female medical students in Turkey ${ }^{12}$ reported that prevalence rate of primary dysmenorrhea is significantly higher in those who had a positive family history when compared to others.

It was found $108(66.7 \%)$ students with primary dysmenorrhea who had positive history in $110 \quad(67.9 \%)$ mothers and $130(80.5 \%)$ sisters were observed with dysmenorrhea. There are only 2 students without dysmenorrhea had positive history of dysmenorrhea in mothers. Therefore, this is summarized that most of women suffer primary dysmenorrhea throughout their reproductive years. In another study done in Selangor, Malaysia ${ }^{14}$ it also shows a significant correlation between a positive family history and primary dysmenorrhoea. It was also reported in a study conducted in Kelantan, Malaysia $^{15}$ that maternal dysmenorrhoea as a risk factor for the occurrence of recurrent

Table 2 Frequency of Severity of Primary Dysmenorrhoea in Students

\begin{tabular}{lccc}
\hline & Pain Scale & Frequency & Percent (\%) \\
\hline No Hurt & 12 & 7.4 \\
Hurts little bit & 40 & 24.7 \\
Hurts little more & 67 & 41.4 \\
Hurts even more & 20 & 12.3 \\
Hurts whole a lot & 16 & 9.9 \\
Hurts worst & 7 & 4.3 \\
Total & 162 & 100 \\
\hline
\end{tabular}


menstrual pain in a family.

Thus, present study shows a strong association between family history and primary dysmenorrhoea.

This result is similar with previous studies done which also found a significant association between family history and recurrent painful menstruation. . $^{3,16,17}$

There are several weaknesses in this study. The data taken from the respondents are solely based on their memory. So, there might be a recall bias. The data regarding the respondent's lifestyle such as smoking and alcohol consumption are inquired in this study. Therefore, some of the respondents might have under reported their behaviour.

This study shows a very high prevalence of dysmenorrhoea among the students, $92.6 \%$ with $95 \%$ confidence interval which is 87.5-95.7\% explains that dysmenorrhoea is a common gynaecology problem. Positive family history of dysmenorrhoea is a significant risk factor for the occurrence of primary dysmenorrhoea in a family. Present study finds a significant association, which proposes that genetic factor is engaged in the pathogenesis of primary dysmenorrhoea and increases the familial predisposition. Therefore, positive family history can be a strong predictor for incidence of dysmenorrhoea in children and siblings.

It is suggested that more research should be done in order to get a better understanding of the positive family history in primary dysmenorrhoea as a risk factor. It is also found that majority of respondents suffered a degree of pain which might interfere the daily activities and reduce their quality of life. Consequently, health care providers should be more sensitive in managing dysmenorrhoea by giving the information that dysmenorrhoea is a common menstrual disorder to the adolescent schoolgirls and encourage them to understand the possible risk factors of dysmenorrhoea and avoid unnecessary suffering and interruptions to their education.

Medical professionals also need to be educated about dysmenorrhoea, its severity and impact on adolescent schoolgirl's daily activities and encourage the medical care providers to screen routinely for dysmenorrhoea among adolescent schoolgirls. They also can offer a treatment to the schoolgirl if it is necessary.

\section{References}

1. Jones R. Oxford textbook of primary medical care: clinical management. reprint ed. United Kingdom: Oxford University Press; 2004. p. 871-2.

2. Balen $\mathrm{AH}$. Reproductive endocrinology for the MRCOG and beyond 2nd ed. The Royal College of Obstetricians and Gynaecologists, London: (RCOG) Press; 2007. p. 53-70.

3. Unsal A, Ayranci U, Tozun M, Arslan G, Calik E. Prevalence of dysmenorrhea and its effect on quality of life among a group of female university students. Ups J Med Sci. 2010;115(2):138-45.

4. Titilayo A, Agunbiade O, Banjo O, Lawani A. Menstrual discomfort and its influence on daily academic activities and psychosocial relationship among undergraduate female students in Nigeria. Tanzan J Health Res. 2009;11(4):181-8.

5. French L. Dysmenorrhea. Am Fam Physician. 2005;71(2):285-91.

6. Charu S, Amita R, Sujoy R, Thomas GA. 'Menstrual characteristics' and 'prevalence and effects of dysmenorrhea'on quality of life of medical students. IJCRIMPH. 2012;4(4):276-94.

7. Care C. Primary dysmenorrhea consensus guideline. J Obstet Gynaecol Can. 2005;27 (12):1117-30.

8. Garra G, Singer AJ, Taira BR, Chohan J, Cardoz H, Chisena E, et al. Validation of the Wong-Baker FACES pain rating scale in pediatric emergency department patients. Acad Emerg Med. 2010;17(1):50-4.

9. Proctor M, Hing W, Johnson TC, Murphy PA, Brown J. Spinal manipulation for dysmenorrhoea (Review). Cochrane Database Syst Rev. 2004;1(3):1-27.

10. Poureslami M, Ashtiani FO. Assessing knowledge, attitude and behavior of adolescent girls in suburban districts of Tehran aboutdysmenorrhea and menstrual hygiene. Journal of International Women's Studies. 2002;3(2):51-61.

11. Proctor M, Farquhar C. Diagnosis and management of dysmenorrhoea. BMJ. 2006;332(7550):1134-8.

12. Unsal A, Ayranci U, Tozun M, Arslan G, Calik E. Prevalence of dysmenorrhea and its effect on quality of life among a group of female university students. Ups J Med Sci. 2010;115(2):138-45.

13. Al-Kindi R, Al-Bulushi A. Prevalence and impact of dysmenorrhoea among Omani high school students. Sultan Qaboos Univ Med J. 2011;11(4):485-91.

14. Liliwati I, Verna L, Khairani O. Dysmenorrhoea and its effects on school 
activities among adolescent girls in a rural school in Selangor, Malaysia. Med \& Health. 2007;2(1):42-7.

15. Zukri SM, Naing L, Hamzah TNT, Hussain NHN. Primary dysmenorrhea among medical and dental university students in Kelantan: prevalence and associated factors. International Medical Journal. 2009;16(2):93-9.
16. Parveen N, Majeed R, Rajar UD. Familial predisposition of dysmenorrhea among the medical students. Pak J Med Sci. 2009; 25(5):857-60.

17. Tavallaee M, Joffres MR, Corber SJ, Bayanzadeh M, Rad MM. The prevalence of menstrual pain and associated risk factors among Iranian women. J Obstet Gynaecol Res. 2011;37(5):442-51. 